\title{
Work Without Jobs
}

\author{
Daniel K. Samaan
}

\begin{abstract}
Technology has always had an impact on the world of work. This chapter compares the transformation of our societies during the Industrial Revolution with potential transformations that digitalization may bring about today. If digitalization is truly disruptive, more may be at stake than job losses in some sectors and job gains in others. Identifying several key features of digitalization, this chapter sketches a future of work in which not jobs but work itself stands in the center of economic activity. Such a development could open a pathway to more humanistic, more democratic, and more sustainable societies but would require rethinking entirely how we organize and reward work on a societal level.
\end{abstract}

Around 200 years ago, many societies in Europe and North America fundamentally altered the way in which work was organized and remunerated. Facilitated by technological advances like the steam and combustion engines, as well as expedited by regulatory changes, mass production and standardization of goods became the prevailing modes of production. This newly emerging factory system also entailed changes in the work organization: it has been characterized by a high physical concentration of labor in production facilities and a hitherto unseen division of labor, orchestrated by hierarchical organizations. Both changes, mechanization and standardization of production processes and the corresponding new work organization, have led to unprecedented productivity gains to which we owe much of today's living standards. In his famous example of the pin factory, Adam Smith has illustrated the magnitude of such productivity increases more than two centuries ago, whereby output per worker could be increased to 4800 pins from less than 20 (Smith 1776).

We all know today that historians would later refer to this decades-long period of continuous and fundamental changes to the world of work as the Industrial Revolution (IR). Closely tied to this revolution is what Frithjof Bergmann (2019) calls the

\footnotetext{
D. K. Samaan $(\bowtie)$

International Labour Organization (ILO), Geneva, Switzerland

e-mail: samaan@ilo.org 
"job system": We bundle the vast majority of our work activities ("tasks") into "jobs." We call standardized descriptions of such jobs "occupations." These jobs are then bought and sold on the (labor) market for a supposedly fair share of society's overall output (wage). Hence, the functioning of the industrial society is centered, not about work that we do for us, but about obtaining and performing jobs for others. The question I want to pursue in this chapter is whether in a "digital society" this interdependence will be any different.

The importance of the "job system" for our societies can hardly be underestimated. It is at the center of how we act and how we conduct our lives: We educate ourselves, predominantly, in order to "learn an occupation" and to "get a job." We want to spend our lives being "employed" and not "unemployed." Being "unemployed" and without a "real job" are social stigmata and lead to loss of income and social standing. Political competition in every Western democracy is critically concerned about creating new jobs or proposing suitable conditions for companies to crank out more jobs. We are prepared to accept all kinds of unpleasant trade-offs, like destroying our environment or heating up the climate, if only job creation is not harmed. Because without jobs, we have no work, no income, no taxes, no public services, no social security systems, no more support for democratic votes, and finally no more society, as we currently know it.

This way of thinking has not changed much since the IR. In 2021, we do reflect about the future of work, but our imagination of the future is restricted and dominated by the "job system" and by all the institutions and terminology that we created around it: "the labor market," "re-skilling," "unemployment," "part-time work," "contingent work," etc. This list could be easily expanded and filled with the respective literature on the future of work. In other words, with some exceptions (e.g., Precht 2018), most of the discussion on the future of work sees the job system as a given centerpiece of our societies.

The job system has not always existed. In pre-industrialization times, working from home or in small community shops on one's own terms, self-controlled and owning the means of production, was the norm. Several factors drove us into the creation of the "job system" at the time.

How does digitalization figure in this debate? It has awakened old fears among workers, politicians, corporate leaders, middle managers, and others. Specifically, they worry that this most recent wave of digitalization will lead to unprecedented automation and hence a massive loss of jobs (Frey and Osborne 2017). And as we have seen above, once the jobs are gone, the downward spiral (no work, no income, etc.) is triggered. So, this fear is justified.

Yet, I would like to look at this question from a slightly different angle in this chapter: A society might run out of jobs, but it can never run out of work. The real question that we face today is therefore whether or not digitalization and its powerful 
offspring, big data and artificial intelligence (AI), ${ }^{1}$ are going to eradicate the "job system" and, if so, how we can live without it.

There are three reasons why digitalization, understood as a technology, has the potential to destroy the job system. Firstly, artificial intelligence is a general-purpose technology (Brynjolfsson and McAfee 2014). It is not an invention, like the radio or many others, which have a confined impact on certain economic sectors and societal domains, like the radio has had on mass media, the printing press, and perhaps the military sector. AI, and digitalization more broadly, is more comparable to electrification. We can find applications and devices in virtually all economic sectors for consumers and producers, workers, management, governments, and many other actors alike. This qualification as a general-purpose technology is a major ingredient for a revolutionary change. The economic system is shocked from many different contact points at the same time.

Secondly, big data provides economic actors ${ }^{2}$ with information on the "states of the world" and facilitates decentralized decision-making and decentralized action. Most of economic activity on the societal level (often also on the individual level) is about making decisions under uncertainty to allocate resources efficiently: A priori, we do not know who needs which goods and services under what conditions at a certain time. Neither do we know who can supply which resources under which conditions and who has which capabilities. We do not know and cannot directly observe in which "state" the world is. This was the price we had to pay for the high division of labor. Traditionally, this lack of information and this problem of coordination have been solved by adding middlemen and by mass-producing a standardized good or service for the average consumer. Those "middlemen" can be persons inside an organization, like middle managers, who pass information from the top management to the workers and make sure the orders are carried out. The middlemen can also be outside an organization (say a firm) and facilitate contact to the right customers or carry out marketing surveys. The information flow and the feedback are typically coordinated through specified channels that follow hierarchical structures. These are remains of the factory system. Digitalization makes much of this framework unnecessary. Production plants and workers do not need to be concentrated, neither spatially nor in time. Output does not have to be standardized but can be customized for a specific individual. We can think about the industrial economic world as a picture of islands of producers, customers, workers, and managers, whereby the middlemen are connecting the islands. The whole picture ("state of the world") is not fully visible. Now big data is rapidly filling the empty spaces with many small dots and establishing direct connections among them.

\footnotetext{
${ }^{1}$ Digitalization encompasses more than the massive amounts of digital data and processing of information through AI systems, but I will have mainly these two aspects in mind when I refer to digitalization in this chapter.

${ }^{2}$ In fact, not all economic actors have the same access to information, and the accumulation of digital data over the last years has already led to a power shift across enterprises.
} 
Thirdly, digitalization brings about an enormous potential to automate tasks. Such automation can but does not have to result in the automation of occupations, as Frey and Osborne (2017) claim. Brynjolfsson et al. (2018) develop a methodology to analyze about 2000 so-called detailed work activities (DWA). These DWA build the backbone of the 1000 occupations that currently exist in the United States. The authors calculate a metric for each DWA that measures to what extent the activity is suitable to machine learning (SML), and since an occupation is just the weighted average of a subset of the DWA, one can also come up with an SML score for each occupation. They find that many US occupations are suitable to machine learning. Unfortunately, such a comprehensive study does not exist for work activities and occupations in countries other than the United States. Furthermore, the analysis is based on existing tasks and on work processes as they exist today. These processes and hence (human) tasks were of course designed in a manner to reflect the capabilities of the currently existing technology (i.e., different technology $=$ different work processes and different tasks). Therefore, one needs to be careful before interpreting the study's results as a prediction for job losses in the US economy or to generalize it to other countries. Yet, the authors demonstrate convincingly how digitalization can lead to a rapid decomposition of a large number of occupations and of existing jobs into underlying tasks. For companies, workers, and governments, this development can lead to a fast destruction of jobs, the emergence of new jobs, and/or a reorganization of work and "re-definition" of jobs.

Taken these three above features of digitalization together, I think, it is very well possible that we will see more than a mere reshuffling of a few lost jobs in some sectors and emerging new jobs other ones, as we have seen in the past. There is potential for-literally - a "digital revolution" in the world of work rather than a slight and continuous adjustment of the status quo. This could become problematic if our societies attempt to cope with this challenge by sticking to the paradigm of the "job system." It seems, however, that this is exactly what policymakers and-to a lesser extent-also enterprises and their people are doing. I am not aware of any country that has proposed a truly new vision for the future of work, other than "lifelong learning" (or "re-skilling"), anemic phrases that have been in use for more than 30 years now. Will that be enough to steer changes in the world of work toward more humanistic, democratic, and sustainable societies?

Going back to my initial statement that a society can never run out of work, this may be a reassuring fallback position; it really cannot, at least theoretically. A society can, however, fail in the coordination of its work potential toward the satisfaction of its material and humanistic needs. This is why we have clung to the job system in the first place: It has provided political stability, kept the masses busy, and provided most of us with an abundance of commodities. It has also created a notion of distributional fairness in presenting itself as a meritocracy.

What is wrong then with the job system? Put bluntly: Almost everybody hates it, and we all know that it is at most partially fair. An increasing number of people feel caught in "bullshit jobs" (Graeber 2018) where they perform objectively or subjectively useless tasks, many of which could be done by machines or only exist to justify the person's "job." Very few people in the workforce do work they "really 
really want" (Bergmann 2019), even though the desire to work and contribute to the well-being of society in one way or another exists in virtually every human being. Is digitalization not giving us the tools to devise a better, more human coordination and remuneration mechanism? According to some estimates, the percentage of jobs in "transaction industries"3 has risen from about $15 \%$ in 1900 to about $40 \%$ in 1970 in the US economy. Unfortunately, I do not have more recent, comparable numbers available, but these estimates were from before the big wave of "servicification" hit our economies. I would therefore estimate that today more than $2 / 3$ of the jobs are "transaction jobs," including a large overlap with what Graeber (2018) calls "bullshit jobs." Karl Marx (1885) referred to labor that is essentially spent to circulate capital and goods as "unproductive labor," compared to "productive labor" that is concerned with the creation of use values for society. ${ }^{4}$ If we adopt this notion of productivity, only a small proportion of all performed labor is still productive for society. Interestingly, going back to the more modern works of Frey and Osborne (2017) and Brynjolfsson et al. (2018), we can see that the jobs/tasks with a high risk of automation and high suitability for machine learning are exactly these jobs/tasks in the "transaction industries." Finally, the job system, conjointly with mass production, has a terrible record in terms of resource productivity. It is a waste producer.

A society with more meaningful and satisfying work is possible. Most of us want to spend more time on care work, education and cultural work, and preserving and protecting our environment. The digital revolution is not threatening our work, it is threatening the job system, and this is good news.

\section{References}

Bergmann, Frithjof (2019): 'New work, new culture - work we want and a culture that strengthens us', Zero Books, Winchester U.K, Washington U.S.

Brynjolfsson, Erik, and Andrew McAfee (2014): 'The Second Machine Age: Work, Progress, and Prosperity in a Time of Brilliant Technologies'. Reprint. W. W. Norton \& Company.

Brynjolfsson, E., T. Mitchell, and D. Rock (2018): 'What Can Machines Learn and What Does It Mean for Occupations and the Economy?' AEA Papers and Proceedings, 108, 43-47.

Frey, Carl Benedikt, and Michael A. Osborne (2017): 'The Future of Employment: How Susceptible Are Jobs to Computerisation?', Technological Forecasting and Social Change 114: 254-80. https://doi.org/10.1016/j.techfore.2016.08.019.

\footnotetext{
${ }^{3}$ Sectors and professions concerned with processing and conveying information (accountants, clerks, lawyers, insurance agents, foremen, guards, etc.).

${ }^{4}$ Marx did not use the terms "productive" and "unproductive labor" consistently throughout all three volumes of capital.
} 
Graeber, David (2018): 'Bullshit Jobs - The rise of pointless work and what we can do about it', Penguin Books, UK, USA.

Marx, Karl (1885): 'Capital', Volume 2, Penguin Edition of 1978, 1885.

Precht, Richard David (2018): 'Jäger, Hirten, Kritiker - Eine Utopie für eine digitale Gesellschaft',

Goldmann Verlag, 1. Auflage, München.

Smith, Adam (1776): 'An Inquiry into the Nature and Causes of the Wealth of Nations', Modern Library; 12/26/93 edition (December 26, 1993), New York.

Open Access This chapter is licensed under the terms of the Creative Commons Attribution 4.0 International License (http://creativecommons.org/licenses/by/4.0/), which permits use, sharing, adaptation, distribution and reproduction in any medium or format, as long as you give appropriate credit to the original author(s) and the source, provide a link to the Creative Commons license and indicate if changes were made.

The images or other third party material in this chapter are included in the chapter's Creative Commons license, unless indicated otherwise in a credit line to the material. If material is not included in the chapter's Creative Commons license and your intended use is not permitted by statutory regulation or exceeds the permitted use, you will need to obtain permission directly from the copyright holder. 